\title{
Programa Permanente de Desenvolvimento Profissional e Formação Pedagógica Docente - PRODOC
}

\author{
Permanent Program of Professional Development and Teacher Education - PRODOC \\ Programa Permanente de Desarrollo Profesional y Formación Pedagógica Docente - PRODOC
} Renata de Almeida Vieira - UNICENTRO | Departamento de Pedagogia | Guarapuava | Paraná | Brasil. E-mail:
realvieira@ gmail.com (1)

Resumo: Este artigo, de natureza bibliográfica e exploratória, é originário de uma pesquisa maior voltada para o mapeamento, em universidades federais mineiras, de programas de formação pedagógica continuada do professor do ensino superior. Seu objetivo é apresentar o resultado de mapeamento realizado junto a uma das instituições abarcadas no processo de levantamento e identificação de programas de desenvolvimento profissional docente. Trata-se da Universidade Federal de Alfenas, situada no sul de Minas Gerais, e seu Programa de Desenvolvimento Profissional e Formação Pedagógica Docente, cujo objetivo consiste na promoção do aprimoramento pedagógico dos docentes da UNIFAL-MG. Mediante o resultado do estudo, destaca-se, dentre outras considerações, que tal Programa de Desenvolvimento Profissional e Formação Pedagógica Docente revela-se como uma iniciativa que coaduna com a atual exigência de formação continuada para a docência na educação superior. E, ainda, que sua institucionalização constitui-se em um importante espaço que aproxima os professores de uma perspectiva de profissionalização da docência.

Palavras-chave: Desenvolvimento profissional docente. Programa de formação pedagógica. Formação continuada.

Abstract: With bibliographic and exploratory nature, this study is part of a broader research aimed at mapping programs of continuing education for teachers of higher education in federal universities in the State of Minas Gerais. It aims to present the results of mapping one of the institutions encompassed in the process of surveying and identifying programs of teacher's professional development. The Universidade Federal de Alfenas, in the South of the State and its Program of Professional Development and Teacher Education, has the objective of promoting pedagogical improvement of its faculty members. According to the results of this study, such Program of Professional Development and Teacher Education proves to be a consistent initiative that meets current requirements of continuing education for teachers in higher education. Also, its institutionalization constitutes an important space that brings teachers closer to a teaching professionalization perspective.

Keywords: Teacher's professional development. Teacher education program. Continuing education.

Resumen: Este artículo, de naturaleza bibliográfica y exploratoria, surge de una investigación mayor inclinada hacia el mapeado en universidades federales mineras de programas de formación pedagógica continuada del profesor de enseñanza superior. Su objetivo es presentar el resultado del mapeamiento_realizado junto a una de las instituciones abarcadas en el proceso de levantamiento e identificación de programas de desarrollo profesional docente. Se trata de la Universidad Federal de Alfenas, situada en el sur de Minas Gerais, y su Programa de Desarrollo Profesional y Formación Pedagógica Docente, cuyo objetivo consiste en la promoción del esmero pedagógico de los docentes de la UNIFALMG. Mediante el resultado del estudio se destaca, de entre otras consideraciones, que tal Programa de Desarrollo Profesional y Formación Pedagógica Docente se revela como una iniciativa que coincide con la actual exigencia de formación continuada para la docencia en la educación superior. Y que su institucionalización se constituyese en un importante espacio que acerca a los profesores hacia una perspectiva de profesionalización de la docencia.

Palabras clave: Desarrollo profesional docente. Programa de formación pedagógica. Formación continuada.

- Recebido em 04 de agosto de 2018 • Aprovado em 02 de maio de $2019 \cdot$ e-ISSN: 2177-5796

DOI: http://dx.doi.org/10.22483/2177-5796.2019v21n2p637-648

Copyright @ 2019. Conteúdo de acesso aberto, distribuído sob os termos da Licença Internaonal da CreativeCommons - CC BY-NC-SA Atribuição Não Comercial (https://br.creativecommons.org/licencas/) - Permite distribuição e reprodução, desde que atribuam os devido créditos à publicação, ao autor(es) e que licenciem as novas criações sob termos idênticos. 
VIEIRA, Renata de Almeida. Programa permanente de desenvolvimento profissional e formação pedagógica docente PRODOC.

\section{Introdução}

Em face de novas demandas e desafios postos aos professores universitários no exercício de sua profissão, entendemos, assim como Almeida (2012); Anastasiou e Alves (2003); Bazzo (2005); Broilo (2007); Broilo e Cunha (2008); Ferenc (2005); Isaia, Bolzan e Maciel (2009); Masseto (2002); Morosini (2003); Pimenta e Almeida (2009, 2011); Veiga e Cunha (1999), que cada vez mais torna-se necessária a formação pedagógica para o ensino na universidade. Entendemos, também, que a criação de espaços e ações formativas que visam tal formação é bem vinda e salutar.

Dentre as iniciativas que caminham em tal direção, destacamos os programas de desenvolvimento profissional de docentes universitários, cuja importância tem sido aos poucos reconhecida por pesquisadores e gestores.

Com o fito de apresentar um programa de formação pedagógica continuada para a docência, que compõe recorte de uma pesquisa mais ampla, de caráter bibliográfico, acerca de políticas institucionais voltadas para o desenvolvimento profissional docente no Estado de Minas Gerais, trazemos à baila o Programa de Desenvolvimento Profissional e Formação Pedagógica Docente - PRODOC desenvolvimento pela Universidade Federal de Alfenas - UNIFAL-MG.

E o que é o PRODOC? Trata-se de um programa de formação pedagógica continuada para a docência que localizamos no processo de levantamento e identificação de universidades mineiras que oferecem ações formativas aos seus docentes, o qual tem por objetivo a promoção do aprimoramento pedagógico de seus professores.

Para discutirmos o tema, inicialmente expomos sobre as mudanças mais amplas relacionadas ao contexto universitário que reivindicam tal aprimoramento, assim como apresentamos a UNIFAL-MG por meio de um breve histórico, a fim de evidenciar a demanda por formação pedagógica de seus docentes. Na sequência, apresentamos seu Programa de Desenvolvimento Profissional e Formação Pedagógica Continuada e considerações acerca da importância da universidade propiciar o aprimoramento e melhoria do processo ensinoaprendizagem e da prática do docente, por meio de ações que promovam o permanente desenvolvimento profissional, formação pedagógica e atualização no campo educacional para o exercício da docência no ensino superior. 
VIEIRA, Renata de Almeida. Programa permanente de desenvolvimento profissional e formação pedagógica docente PRODOC.

\section{Desafios e demandas postos ao contexto universitário}

Reconhecemos que a universidade, termo que aqui utilizamos de forma genérica para nos referir às instituições de Ensino Superior, tem enfrentado muitos desafios como, por exemplo, a dicotomia entre sua função de profissionalizar e a de produzir conhecimentos, a sua organização interna frente às demandas externas, entre tantos outros. Ademais, enfrenta-se a fenômenos contraditórios como é a globalização e a regionalização, a democratização e a marginalização, que implicam a necessidade de repensar sua atuação.

Ainda que essa situação não seja nova, esse processo de rever sua atuação e adaptar-se “[...] às circunstâncias e às demandas da sociedade acelerou-se tanto nesse último meio século, que é impossível um ajuste adequado sem uma transformação profunda das próprias estruturas internas das universidades" (ZABALZA, 2004, p. 19). Em ritmo de marcha forçada estamos a incorporar "[...] mudanças na estrutura, nos conteúdos e nas dinâmicas de funcionamento das instituições universitárias com o objetivo de colocá-las em condição de enfrentar os novos desafios que as forças sociais lhes obrigam a assumir" (ZABALZA, 2004, p. 19).

A universidade, consoante Zabalza (2004, p. 20), tem sido "[...] foco de dinâmicas que se entrecruzam e que estão provocando o que alguns não vacilam em descrever como uma autêntica 'revolução' da educação superior”. Exemplifica, sobre isso, que “a própria legislação foi modificando, nos últimos anos, a gama de atribuições e expectativas sobre a universidade: o que deveria ser, os novos desafios sociais a que deverá responder, as condições sob as quais se supõe que tem de funcionar" (ZABALZA, 2004, p. 20). Desse modo, encontra-se em transformação a habitual imagem que se tinha da universidade como uma instituição dedicada a ministrar um alto ensino para formar os líderes do mundo social e do mundo científico e artístico.

A esse respeito, observamos que um dos desafios posto à universidade é a superação de um tipo de representação ainda usual de ensino universitário pautado na transmissão mecanicista de conhecimentos e em uma relação unidirecional.

Trata-se, por certo, de herança de outro momento histórico em que a universidade atendia a uma clientela seleta, tinha caráter elitista e se constituía em produtora e difusora de conhecimentos científicos, humanístico, da alta cultura, bem como garantidora da permanência de práticas pedagógicas consolidadas tradicionalmente. 
VIEIRA, Renata de Almeida. Programa permanente de desenvolvimento profissional e formação pedagógica docente PRODOC.

Acerca das mudanças mais amplas relacionadas ao contexto universitário, Santos (2005, p. 8) contribui para esta reflexão ao avaliar que desde o final do século $\mathrm{XX}$ a universidade - em crise de hegemonia, resultante de contradições entre suas funções tradicionais - passa a se ocupar da “[...] produção de padrões culturais médios e de conhecimentos instrumentais, úteis na formação de mão de obra qualificada exigida pelo desenvolvimento capitalista”.

$\mathrm{Na}$ realidade, a clientela atendida por essa nova universidade amplia-se. Por meio de políticas de democratização da universidade, de reivindicação da igualdade de oportunidades para os filhos das classes populares, estudantes de baixa renda, de áreas rurais, minorias étnicas, que outrora estavam à margem desse nível de escolarização, passam a ser incorporados.

O professor, mediante essa nova configuração da universidade, é convocado a assumir papel de mediador entre a compreensão cultural dos jovens e as informações disponíveis. Este novo papel contraria a representação ainda usual de docência universitária orientada pela transmissão de saberes profissionais e acadêmicos, transmissão essa que seria a principal fonte de informação dos universitários (RIBEIRO; CUNHA, 2010).

É possível observar, nesse ponto, um impasse entre o modelo clássico de professor universitário e a nova função da universidade e a clientela que passa a ser atendida.

Acerca desse modelo clássico de constituição universitária, Cortesão (2000, p. 40) expõe que a universidade, orientada pela "[...] preocupação de universalidade, se constitui como que o bastião da uniformidade de ordenação da transmissão e globalização dos conteúdos e processos que se revelam, algumas vezes, pouco adequados ao quadro atual em que se insere". Nesse sentido, a autora constata que "os docentes universitário ensinam geralmente como foram ensinados, garantindo, pela sua prática, uma transmissão mais ou menos eficiente de saberes e uma socialização idêntica àquela de que eles próprios foram objeto" Cortesão (2000, p. 40). Todavia, em meio às mudanças que estão se processando, passa-se a requerer outro modelo de professor que supere tal postura.

Uma das frentes que tem figurado como alternativa a tal impasse, isto é, novos desafios versus antigas práticas, consiste em promover a formação inicial e/ou continuada do professor do ensino superior atinente aos desafios atuais. É em resposta a tal panorama que situamos a criação de programas visam sua formação pedagógica continuada.

Sobre tais programas, estes podem ser definidos como espaços para a reflexão, discussão e atualização da prática pedagógica, assim como de outros aspectos que compõem o contexto do 
VIEIRA, Renata de Almeida. Programa permanente de desenvolvimento profissional e formação pedagógica docente PRODOC.

ensino superior. Buscam atender tanto aos interesses mais imediatos dos docentes como intencionam instigar, incomodar, expandir horizontes, apresentar possibilidades e alternativas, bem como antecipar discussões e decisões (PACHANE, 2003, 2006).

O PRODOC da Universidade Federal de Alfenas é, pois, um desses programas de formação continuada. Antes de apresentá-lo aproximamo-nos à contextura da qual emerge a demanda por formação pedagógica por parte da UNIFAL-MG.

\section{A UNIFAL e a demanda por formação pedagógica}

A Universidade Federal de Alfenas - UNIFAL-MG, situada no sul do Estado de Minas Gerais, foi fundada em 03 de abril de 1914 como Escola de Farmácia e Odontologia de Alfenas EFOA e constituída sob a forma de Autarquia, em Regime Especial, pelo Decreto n 70.686/72. A sua fundação ocorreu com a implantação do Curso de Bacharelado em Farmácia e no ano de 1973 implantou-se o Curso de Bacharelado em Odontologia (UNIFAL-MG, 2013).

A federalização da EFOA ocorreu em 1960 por meio da Lei n ${ }^{\circ}$ 3854, de 18 de dezembro e em 1972 foi transformada em Autarquia de Regime Especial por meio do Decreto $n^{\circ}$ 70.686, o qual favoreceu a implantação do curso de Enfermagem e Obstetrícia, autorizado pelo Parecer $n^{\circ}$ 3.246, de 5 de outubro de 1976, e pelo Decreto $\mathrm{n}^{\circ} 78.949$, de 15 de dezembro de 1976, e reconhecido pelo Parecer do CFE no $1.484 / 79$ e pela Portaria MEC n 1.224 , de 18 de dezembro de 1979.

Somente em 1999 foram implantados os cursos Nutrição, Ciências Biológicas e a modalidade Fármacos e Medicamentos, para o curso de Farmácia, todos autorizados pela Portaria do MEC 1.202, de 03 de agosto de 1999 e iniciados no ano 2000.

Mediante tal ampliação de cursos, a instituição foi transformada em Centro Universitário Federal - EFOA/CEUFE, um ano após o início dos novos cursos, por meio da Portaria do MEC $\mathrm{n}^{\mathrm{o}} 2.101$, de $1^{\mathrm{o}}$ de outubro de 2001 .

Em atendimento às exigências legais das Diretrizes Curriculares para os cursos de Ciências Biológicas, o curso de Biologia foi desmembrado em modalidades, originando os cursos de Ciências Biológicas - Licenciatura, com início no segundo semestre de 2002, e Ciências Biológicas - Bacharelado, com início no primeiro semestre de 2003. Em 2003 teve também início o curso de Química - Bacharelado, ampliando a área de atuação da Instituição. 
VIEIRA, Renata de Almeida. Programa permanente de desenvolvimento profissional e formação pedagógica docente PRODOC.

Dois anos mais tarde, a EFOA/CEUFE foi transformada em Universidade Federal de Alfenas - UNIFAL- MG, por meio da Lei Federal $n^{\circ} 11.154$, de 29 de julho de 2005. No ano de 2006/2007, como resultado da participação da UNIFAL-MG no Programa de Expansão do Ensino Superior coordenado pelo MEC, foram criados os cursos de Ciências da Computação, de Licenciatura em Física, de Licenciatura em Matemática e de Licenciatura em Pedagogia, além da ampliação do número de vagas para do curso de Química - Bacharelado.

Em continuidade ao processo de expansão, a UNIFAL-MG implantou, em 2007, os cursos de Química - Licenciatura, de Geografia - Bacharelado e Licenciatura, de Biotecnologia, as ênfases em Ciências Médicas e Ciências Ambientais no curso de Ciências Biológicas e ampliou a oferta de vagas para o curso de Nutrição. Em março deste mesmo ano o número de alunos matriculados já chegava a 1.779, sendo que 293 (16,5\%) dos matriculados estavam no período noturno.

Em 2008, o curso de Ciências Biológicas com ênfase em Ciências Médicas foi alterado para Biomedicina e, no primeiro semestre de 2009, foram inaugurados os cursos de licenciatura em História, em Letras (com bacharelado), em Ciências Sociais (também como bacharelado) e o curso de Fisioterapia. Além dos cursos de graduação, houve ainda a expansão dos cursos de pósgraduação strictu sensu com a criação de novos cursos de mestrados e doutorados.

As tendências de expansão das Instituições Federais de Ensino Superior, aliadas às demandas regionais do Sul de Minas, levaram a UNIFAL-MG, em 2009, à criação de dois novos campi nas cidades de Varginha e Poços de Caldas, além de outro campus em Alfenas. No Campus de Varginha foram criados os cursos de Bacharelado Interdisciplinar em Ciência e Economia, Ciências Atuariais, Administração Pública e Ciências Econômicas e em Poços de Caldas, os cursos de Bacharelado Interdisciplinar em Ciência e Tecnologia, Engenharia Urbana e Ambiental, Engenharia de Minas e Engenharia Química, com início no primeiro semestre de 2009.

O cenário político-social do sul e sudeste de Minas Gerais propiciou discussões entre as universidades federais dessa região, resultando, em junho de 2011, na aprovação, pelo Conselho Universitário, da participação da UNIFAL-MG em um consórcio de universidades com vista à criação de potenciais cursos de graduação para expansão universitária como, por exemplo, Medicina, Filosofia, Terapia Ocupacional, Geologia e Serviço Social (UNIFAL-MG, 2013). 
VIEIRA, Renata de Almeida. Programa permanente de desenvolvimento profissional e formação pedagógica docente PRODOC.

No que toca à pós-graduação strictu sensu, constatamos que estão previstos os seguintes cursos: mestrados em Energia e Sustentabilidade, Ciências e Engenharia Ambiental, em Poços de Caldas, mestrado em Gestão Pública e Sociedade em Varginha e, em Alfenas, mestrados em Educação, Estudos Culturais, Ciências Odontológicas, Biometria e Matemática Aplicada e Física, além dos doutorados em Biociências e Química.

Diante dos desafios da expansão e preocupada em manter a sua reconhecida qualidade e bons resultados em seus cursos de graduação e pós-graduação, a UNIFAL-MG tem buscado uma constante melhoria do ensino universitário.

Tal busca revela-se, entre outros meios, pelo estabelecimento de diretrizes pedagógicas que define inovações significativas em relação à flexibilidade dos componentes curriculares, a ampliação da discussão de metodologias ativas e interdisciplinaridade. E, ainda, desenvolvimento de materiais pedagógicos por meio de grupos de estudos para a aplicação de metodologias inovadoras, dentre elas a metodologia da problematização, incorporação de avanços tecnológicos com a utilização de Educação a Distância, entre outros.

Observamos que se trata de diretrizes que visam fomentar a inovação pedagógica na Universidade. Tal inovação, no entanto, não dispensa a atualização do docente para sua consecução. É nesse contexto que situamos o Programa Permanente de Desenvolvimento Profissional e Formação Pedagógica - PRODOC da UNIFAL-MG.

\section{Sobre o Programa Permanente de Desenvolvimento Profissional e Formação Pedagógica - PRODOC}

Constatamos em nossa investigação que o Programa Permanente de Desenvolvimento Profissional e Formação Pedagógica de Docentes foi aprovado por meio da Resolução Nº 009, de 18 de maio de 2011 (UNIFAL-MG, 2011) e complementa a qualificação do corpo docente da UNIFAL-MG. Trata-se de um Programa apresentado pela Pró-Reitoria de Graduação PROGRAD e integra o Plano Anual de Capacitação Docente.

O PRODOC tem por objetivo propiciar aos docentes da UNIFAL-MG oportunidades de aprimoramento, de atualização e de melhoria do processo ensino-aprendizagem e da prática docente. Por meio de oficinas, cursos, seminários, entre outras ações da mesma natureza, busca abordar a organização e gestão da estrutura acadêmica e administrativa da instituição, os 
VIEIRA, Renata de Almeida. Programa permanente de desenvolvimento profissional e formação pedagógica docente PRODOC.

fundamentos educacionais do ensino superior, as bases epistemológicas, sociais e culturais do desenvolvimento desse nível de ensino, assim como recursos, inovações e metodologias educacionais.

Observamos que as oficinas, cursos, seminários e demais ações do Programa relacionadas ao atendimento da dimensão "organização e gestão da estrutura acadêmica e administrativa da Universidade", busca, entre outras coisas, promover a ambientação do docente ao local e às condições de trabalho, de modo a facilitar sua integração aos demais servidores e nortear sua vida funcional junto à Instituição.

Já no que se refere às bases epistemológicas, sociais e culturais do ensino superior, o objetivo é promover reflexões sobre a docência nos diferentes contextos de atuação profissional desta atividade, articulando ensino, pesquisa e extensão.

No tocante as bases educacionais, o que se visa é discutir temas relacionados aos fundamentos legais, normativos do funcionamento e de avaliação/supervisão educacional dos cursos de graduação, bem como a reflexão sobre a docência e sua relação com os paradigmas emergentes e políticas educacionais em vigor vinculadas à educação superior.

Sobre os recursos e inovações metodológicas, o Programa busca contemplar temas relacionados diretamente a prática pedagógica e a atuação do docente no ensino superior.

Em síntese, destacamos que o conjunto de oficinas, cursos, seminários e demais ações desenvolvidos pelo PRODOC, deve garantir que sejam propiciados instrumentos de formação que possibilitem ao docente uma ampla visão da realidade da Instituição, destacando a explanação de sua estrutura, seus objetivos, Programas e Planos. Assim como uma abordagem dos elementos pedagógicos indispensáveis ao exercício da carreira de docente no ensino superior, enfatizando aspectos que aprimorem o processo ensino-aprendizagem e permitam a manutenção do padrão de qualidade do ensino praticado nos cursos e programas oferecidos pela UNIFALMG.

Observamos, ademais, que a elaboração e execução de suas atividades buscam envolver tanto os membros dos corpos docentes e técnico administrativo, como também a Diretoria da Unidade Acadêmica de lotação dos docentes, Coordenações de Cursos de Graduação, PróReitoria de Pós-Graduação e Pesquisa, Pró-Reitoria de Extensão, Pró-Reitoria de Gestão de Pessoas, Biblioteca, Departamento de Registros Gerais e Controle Acadêmico, entre outros órgãos e seus respectivos responsáveis. 
Embora endereçado a todo o corpo docente, sublinhamos que o PRODOC visa especialmente os docentes em estágio probatório. Conforme resolução, “[...] a partir do primeiro semestre de exercício profissional na Universidade Federal de Alfenas, UNIFAL-MG, os docentes admitidos na condição de professores efetivos em estágio probatório, deverão obrigatoriamente, cumprir o Programa [...]” (UNIFAL-MG, 2011, p. 1). Além disso, consta que “[...] o docente já aprovado em estágio probatório que obtiver, em pelo menos duas avaliações institucionais consecutivas, um resultado não satisfatório, conforme critério estabelecido pela Comissão Própria de Avaliação [...] deverá participar das ações [...]” (UNIFAL-MG, 2011, p. 1) do PRODOC, se sua participação for recomendada pelo diretor da unidade acadêmica onde esteja lotado, em conjunto, no mínimo, com um coordenador do curso onde atuou como docente no período destas avaliações, que recomendarão as dimensões e a carga horária necessárias para sua atualização (UNIFAL-MG, 2011, p. 1).

Para os demais docentes já aprovados no estágio probatório a participação no Programa é livre e voluntária, podendo a certificação ser aproveitada na progressão na carreira.

Sobre a natureza do PRODOC, compreendemos que tal iniciativa motiva os professores a focalizar a atenção na prática docente e nas intenções de ensino, assim como incentiva a criação de espaços de reflexão crítica que auxiliam no desenvolvimento da consciência do trabalho docente. Ademais, contribui para o desenvolvimento da profissionalidade docente à medida que se compartilha problemas, discute e contrasta pontos de vistas teóricos, bem como se analisa fatores que condicionam a atividade de ensinar.

Reconhecemos que tal Programa viabiliza o que Souza (2011) aponta como criação de espaços e situações que contribuem para ampliar o repertório de saberes docentes, aliando o que fazem enquanto docentes às teorias pedagógicas. Ademais, possibilita aproximá-los de uma perspectiva de profissionalização da docência, conforme apontam Almeida (2007), Anastasiou (1998), Cunha (2005, 2007, 2008), Esteves (2008), Formosinho (2009), Pimenta e Anastasiou (2002), entre outros estudiosos da temática.

\section{Considerações finais}

Reiteremos que em meio a um panorama de complexificação das relações sociais, laborais, culturais e educativas novas demandas são criadas e apresentadas às instituições sociais, entre elas a universidade. 
VIEIRA, Renata de Almeida. Programa permanente de desenvolvimento profissional e formação pedagógica docente PRODOC.

Como parte da totalidade social, a universidade, encontra-se incorporada à tessitura contraditória da sociedade em relações de mútuas interatuações (DIAS SOBRINHO, 2000, 2005). Considerada sua função de caráter ético e político, entendemos que sua responsabilidade social não se pode resumir à função instrumental de capacitação técnica e de treinamento de profissionais para as empresas, já que se trata de um instrumento de sustentação do desenvolvimento humano. Por isso mesmo identificar caminhos alternativos e novas prioridades em prol de seu desenvolvimento torna-se urgente.

A configuração de espaços formativos, como o que identificamos no PRODOC, para reflexão sobre a prática docente e busca de caminhos para o enfrentamento dos desafios inerentes à docência universitária certamente é salutar e necessário.

Com o estudo do PRODOC, constatamos entre outras coisas o investimento por parte da UNIFAL-MG no que se refere à promoção de ações de formação continuada por meio de seu programa de desenvolvimento profissional docente, ações estas sintonizadas com os desafios do ensinar na universidade.

Sobre o PRODOC, consideramos que uma de suas características marcante é a criação de uma cultura institucional sintonizada com uma formação consistente e com legitimidade, já que cria abertura para os docentes expressarem suas reais necessidades pedagógicas.

Consideramos, ainda, que tal Programa revela-se como uma iniciativa que coaduna com a atual exigência de formação continuada do docente da Educação Superior. Isto porque cada vez mais se põe como exigência aos professores o desenvolvimento de competências pedagógicas para além dos seus conhecimentos científicos e técnicos.

Nesse sentido, torna-se imperioso que os docentes explicitem suas opções e as razões que presidem as suas decisões sobre o que ensinam e como ensinam. A formação pedagógica é, portanto, uma tendência cada vez mais recomendada por pesquisadores da temática docência universitária, bem como aceita e incentivada pelas próprias instituições de ensino superior.

\section{Referências}

ALMEIDA, M. I. Formação do professor do ensino superior: desafios e políticas institucionais. São Paulo: Cortez, 2012.

ALMEIDA, M. I. Pedagogia universitária: demandas e possibilidades na formação contínua do docente universitário. Relatório de Pesquisa (Pós-Doutoramento) - Universidade Autônoma de Barcelona, Barcelona, Espanha, 2007. 
VIEIRA, Renata de Almeida. Programa permanente de desenvolvimento profissional e formação pedagógica docente PRODOC.

ANASTASIOU, L. G. C. Metodologia do ensino superior: da prática docente a uma possível teoria pedagógica. Curitiba: IBPEX, 1998.

ANASTASIOU, L. G. C.; ALVES, L. P. Processos de ensinagem na universidade. Joinville: Univille, 2003.

BAZZO, V. L. Uma experiência de formação para professores do ensino superior. In: REUNIÃO ANUAL DA ANPED, 28., 2005, Caxambu. Caxambu, MG. Anais [...] Caxambu, MG: Caxambu, 2005.

BROILO, C. L. (Con)formando o trabalho docente: ação pedagógica na universidade - UNISINOS. In: REUNIÃO ANUAL DA ANPED, 30., 2007, Caxambu. Caxambu, MG. Anais [...] Caxambu, MG: Caxambu, 2007.

BROILO, C. L.; CUNHA, M. I. da. Pedagogia universitária e produção de conhecimento. Porto Alegre: Edipcrs, 2008.

CORTESÃO, L. Ser professor: um ofício em risco de extinção? Porto, Portugal: Afrontamento, 2000.

CUNHA, M. I. da. O professor universitário: na transição de paradigmas. 2. ed. Araraquara: Junqueira \& Marin, 2005.

CUNHA, M. I. da. Pedagogia universitária: energias emancipatórias em tempos neoliberais. Araraquara: Junqueira \& Marin, 2008.

CUNHA, M. I. da. Reflexões e práticas em pedagogia universitária. Campinas: Papirus, 2007.

DIAS SOBRINHO, J. Avaliação da educação superior. Petrópolis: Vozes, 2000.

DIAS SOBRINHO, J. Educação superior, globalização e democratização. Qual universidade? Revista Brasileira de Educação, Rio de Janeiro, n. 28, p. 164-173, jan./abr. 2005.

ESTEVES, M. Para a excelência pedagógica do ensino superior. Sísifo: Revista de Ciências da Educação, Lisboa, Portugal, n. 7, p. 101-109, set./dez. 2008.

FERENC, A. V. F. Como o professor universitário aprende a ensinar? Um estudo na perspectiva da socialização profissional. 2005. 298p. Tese (Doutorado em Educação) - Programa de Pós-graduação em Educação, Universidade Federal de São Carlos, São Carlos, 2005.

FORMOSINHO, J. (org.). Formação de professores: aprendizagem profissional e acção docente. Porto, Portugal: Porto, 2009.

ISAIA, S. M. A.; BOLZAN, D. P. V.; MACIEL, A. M. R. (org.). Pedagogia universitária: tecendo redes sobre a educação superior. Santa Maria: EdUFSM, 2009.

MASSETO, M. T. Professor universitário: um profissional da educação na atividade docente. In: MASSETO, M. T. (org.). Docência na universidade. 2. ed. Campinas, SP: Papirus, 2002. p. 9-26.

MOROSINI, M. C. (org.). Enciclopédia da pedagogia universitária. Porto Alegre: FAPERGS/RIES, 2003.

PACHANE, G. G. A importância da formação pedagógica para o professor universitário: a experiência da UNICAMP. 2003. 268 f. Tese (Doutorado em Educação) - Faculdade de Educação, Universidade Estadual de Campinas, Campinas, 2003.

PACHANE, G. G. Teoria e prática na formação de professores universitários: elementos para discussão. In: RISTOFF, D.; SEVEGNANI, P. (orgs.). Docência na educação superior. Brasília: INEP, 2006. p. 97-146.

PIMENTA, S. G.; ALMEIDA, M. I. (org.). Pedagogia universitária. São Paulo: EdUSP, 2009. 
VIEIRA, Renata de Almeida. Programa permanente de desenvolvimento profissional e formação pedagógica docente PRODOC.

PIMENTA, S. G.; ALMEIDA, M. I. (org.). Pedagogia universitária: caminhos para a formação de professores. São Paulo: Cortez, 2011.

PIMENTA, S. G.; ANASTASIOU, L. das G. C. Docência no ensino superior. São Paulo: Cortez, 2002.

RIBEIRO, M. L.; CUNHA, M. I. da. Trajetórias da docência universitária em um programa de pósgraduação em saúde coletiva. Interface - Comunic., Saúde, Educ., Botucatu, v. 14, n. 32, p. 55-68, jan./mar. 2010.

SANTOS, B. S. A universidade no século XXI: para uma reforma democrática e emancipatória da Universidade. São Paulo: Cortez, 2005.

SOUSA, Walêska Dayse Dias de. Identidade profissional docente no curso de medicina da Universidade Federal do Triângulo Mineiro. 2011. 158 f. Dissertação (Mestrado em Educação) Programa de Pós-Graduação em Educação, Universidade Federal de Uberlândia, Uberlândia, 2011.

UNIVERSIDADE FEDERAL DE ALFENAS -MG. Resolução $\mathbf{n}^{\circ} 009$ de 18 de maio de 2011. Institui o Programa Permanente de Desenvolvimento Profissional e Formação Pedagógica da UNIFAL-MG PRODOC. Alfenas: UNIFAL-MG, 2011.

UNIVERSIDADE FEDERAL DE ALFENAS - MG. Plano de Desenvolvimento Institucional - PDI 2011-2015. Alfenas: UNIFAL-MG, 2013.

VEIGA, I. P. A.; CUNHA, M. I. da. (org.). Desmistificando a profissionalização do magistério. Campinas: Papirus, 1999.

ZABALZA, M. A. O ensino universitário: seu cenário e seus protagonistas. Porto Alegre: Artmed, 2004. 